Article

\title{
Variation of Surface Nanostructures on (100) PbS Single Crystals during Argon Plasma Treatment
}

\author{
Sergey P. Zimin ${ }^{1,2}$, Nikolai N. Kolesnikov ${ }^{3}$, Ildar I. Amirov ${ }^{1}$, Viktor V. Naumov ${ }^{1}{ }^{\circledR}$, Egor S. Gorlachev ${ }^{1}$, \\ Sara Kim ${ }^{4}$ and Nam-Hoon Kim ${ }^{4, *(\mathbb{D})}$
}

Citation: Zimin, S.P.; Kolesnikov, N.N.; Amirov, I.I.; Naumov, V.V.;

Gorlachev, E.S.; Kim, S.; Kim, N.-H. Variation of Surface Nanostructures on (100) PbS Single Crystals during Argon Plasma Treatment. Crystals 2022, 12, 111. https://doi.org/ $10.3390 /$ cryst 12010111

Academic Editors:

Tomasz Bartkowiak, Paweł Zmarzły, Damian Gogolewski and

Tomasz Kozior

Received: 14 December 2021

Accepted: 12 January 2022

Published: 15 January 2022

Publisher's Note: MDPI stays neutral with regard to jurisdictional claims in published maps and institutional affiliations.

Copyright: (c) 2022 by the authors. Licensee MDPI, Basel, Switzerland. This article is an open access article distributed under the terms and conditions of the Creative Commons Attribution (CC BY) license (https:/ / creativecommons.org/licenses/by/ $4.0 /)$.
1 Yaroslavl Branch of the Valiev Institute of Physics and Technology of Russian Academy of Sciences, Yaroslavl 150007, Russia; ildamirov@yandex.ru (I.I.A.); vvnau@rambler.ru (V.V.N.); em51@mail.ru (E.S.G.)

2 Microelectronics and General Physics Department, P.G. Demidov Yaroslavl State University, Yaroslavl 150003, Russia; zimin@uniyar.ac.ru

3 Institute of Solid State Physics of Russian Academy of Sciences, Chernogolovka 142432, Russia; nkolesn@issp.ac.ru

4 Department of Electrical Engineering, Chosun University, Gwangju 61452, Korea; sarakim@chosun.kr * Correspondence: nhkim@chosun.ac.kr; Tel./Fax: +82-62-230-7028

\begin{abstract}
The nanostructuring of the (100) PbS single crystal surface was studied under varying argon plasma treatment conditions. The initial $\mathrm{PbS}$ single crystals were grown by high-pressure vertical zone melting, cut into wafer samples, and polished. Subsequently, the PbS single crystals were treated with inductively coupled argon plasma under varying treatment parameters such as ion energy and sputtering time. Plasma treatment with ions at a minimum energy of $25 \mathrm{eV}$ resulted in the formation of nanotips with heights of 30-50 nm. When the ion energy was increased to $75-200 \mathrm{eV}$, two types of structures formed on the surface: high submicron cones and arrays of nanostructures with various shapes. In particular, the 120 s plasma treatment formed specific cruciform nanostructures with lateral orthogonal elements oriented in four $<100>$ directions. In contrast, plasma treatment with an ion energy of $75 \mathrm{eV}$ for $180 \mathrm{~s}$ led to the formation of submicron quasi-spherical lead structures with diameters of 250-600 nm. The nanostructuring mechanisms included a surface micromasking mechanism with lead formation and the vapor-liquid-solid mechanism, with liquid lead droplets acting as self-forming micromasks and growth catalysts depending on the plasma treatment conditions (sputtering time and rate).
\end{abstract}

Keywords: lead sulfide; single crystal; plasma treatment; inductively coupled plasma; nanostructures; submicron cones; vapor-liquid-solid mechanism

\section{Introduction}

In recent years, significant research interest has been directed towards the formation and application of nanostructured materials based on lead chalcogenides ( $\mathrm{PbX}, \mathrm{X}=\mathrm{S}, \mathrm{Se}$, and $\mathrm{Te}$ ) [1,2]. The unique properties of these materials are associated with with their large exciton Bohr radii (18-50 $\mathrm{nm}$ ) and the generation of multiple excitons. In addition, wide variety of synthesis methods capable of controlled formation of nanostructures with various shapes and sizes opens broad prospects for practical application [3-5]. PbX nanostructures can be formed by a large number of methods, including hydrothermal method [6], hightemperature synthesis [7], synthesis in aqueous solutions [8], molecular beam epitaxy [9], and synthesis in polymer and glass matrices $[10,11]$. Low-temperature ion and ion-plasma treatments are particularly attractive [12]. During interaction of ions with the surface, different surface nanostructure formation mechanisms are possible [13-19], which makes ion and ion-plasma techniques an important tool for surface nanostructuring. We used binary compounds of $\mathrm{PbX}$ and ternary solid solutions based on them as examples to show that varying inductively coupled argon plasma treatment condition enables the formation of micro- and nanostructures [20-27]. These nanostructures exhibit various morphologies on the surface 
of single crystals and mono- and polycrystalline films of lead chalcogenides, which can influence the optical properties of modified systems. Notably, plasma treatment results in fundamentally new surface structures that are not observed with common synthesis and epitaxy. In contrast to typical synthesis methods that require an additional step to deposit nanostructures on a substrate, plasma treatment enables the formation of nanostructures directly on the surface. Using this method, various micro- and nanostructures have been successfully formed such as nanotip arrays, high submicron cones, arrays of "capped" conical nanostructures, ensembles of hollow metallic quasi-spherical structures etc. The physical mechanisms underlying such formations could be different; for example, high submicron cones were formed at dislocations by micromasking mechanism, whereas capped conical nanostructures grew on the surface by the vapor-liquid-solid (VLS) mechanism. A novel plasma-assisted self-formation of nanostructures via VLS mechanism with selfforming lead-enriched catalytic droplets has been demonstrated for $\mathrm{PbX}$ binary and ternary compounds [24,27]. Specifically, the sputtered material was redeposited on a heated surface in the form of "building blocks" consisting of both binary $\mathrm{PbX}$ molecules and atomic lead, which formed nano- and microstructures on the surface. In our previous studies [20-27], only a certain set of conditions were considered for the ion-plasma treatment, leading to specific types of nanostructures. Alternatively, in the present work for the first time, various plasma treatment conditions have been employed in the ion energy range of 25-200 eV, and the physical processes occurring during surface modification have been analyzed using the crystals of one specific material: $\mathrm{PbS}$. Considering that the formation of $\mathrm{PbS}$ nanostructures strongly depends on the synthesis conditions [28-30], one can anticipate that changing the plasma treatment conditions will result in various surface morphologies. Therefore, this work aims to study the formation of micro- and nanostructures on the surface of (100) PbS single crystals under various argon plasma treatment conditions.

\section{Materials and Methods}

$\mathrm{PbS}$ single crystals were grown by the high-pressure vertical zone melting in the argon medium. This method has been previously applied to successfully grow other metal chalcogenides [31]. PbS for the initial load was synthesized from pure elemental powders, and the crucible and resistive heater used for the growth process were of high-purity graphite. The argon pressure during the growth run was $1.2 \mathrm{MPa}$ and the rate of zone movement was $2 \mathrm{~mm} \mathrm{~h}^{-1}$. The crystals were characterized by the [100] crystallographic direction along the growth axis; the chemical composition inclined slightly toward a metal component (S 49.05 at.\% and $\mathrm{Pb} 50.95$ at.\%). The dislocation density determined by selective chemical etching of crystal cleavages perpendicular to the growth directions was approximately $6 \times 10^{4} \mathrm{~cm}^{-2}$. The initial $\mathrm{PbS}$ wafer samples were prepared by cutting the as-grown (100)-oriented crystals using a tension blade (thickness $0.45 \mathrm{~mm}$, internal cutting edge, diamond 60/40) and subsequent grinding, mechanical polishing using a diamond paste, and chemical wet cleaning of the surface. Selective etching studies have shown that the dislocation density in a thin near-surface layer that is mechanically damaged during polishing reaches $\sim 10^{8} \mathrm{~cm}^{-2}$.

The (100) PbS single crystals were treated in argon plasma in a high-density lowpressure radio frequency (RF) inductively coupled plasma reactor, which is described in detail in our review [12]. Argon plasma was ignited by applying an RF power of $800 \mathrm{~W}$ (frequency $13.56 \mathrm{MHz}$ ) to the inductor. The RF bias power, which was separately applied to the substrate holder, was varied in the range of $0-200 \mathrm{~W}$ (frequency $13.56 \mathrm{MHz}$ ). This resulted in a negative self-bias potential $U_{\mathrm{sb}}$, which was measured with a voltmeter. For the RF bias power equal to $0 \mathrm{~W}$ the average $\mathrm{Ar}^{+}$ion energy $E_{\mathrm{i}}$ was determined by the plasma potential $U_{\mathrm{p}}$, which was $\sim 25 \mathrm{~V}$. $E_{\mathrm{i}}$ was calculated according to $E_{\mathrm{i}}=\mathrm{e}\left(U_{\mathrm{sb}}+U_{\mathrm{p}}\right)$ and was controlled by the RF bias power applied on the substrate, and it was in the range of $25-200 \mathrm{eV}$ in this work. Ions bombarded the surface at the normal angle. The ion current density was $7.5 \mathrm{~mA} \mathrm{~cm}^{-2}$. Argon gas (purity 99.99\%) flow was set to $10 \mathrm{sccm}$ and an 
operating gas pressure of $0.08 \mathrm{~Pa}$. The plasma treatment duration was varied in the range of 60-300 s.

The surface morphology of the PbS single crystals was studied with scanning electron microscopy (SEM) using a Supra 40 Carl Zeiss microscope. The local chemical composition of the crystal surface was determined using energy-dispersive X-ray (EDX) microanalysis using an INCAx-act spectrometer (Oxford Instruments).

\section{Results and Discussion}

\subsection{Sputtering Rates of PbS Single Crystals in Argon Plasma with Varying Ar ${ }^{+}$Ion Energy}

During the plasma treatment, the sample surface was basically bombarded with normally incident $\mathrm{Ar}^{+}$ions. The surface got heated on irradiation by ultraviolet (UV) emission (glow) from the argon plasma. A specific feature of $\mathrm{PbX}$ materials is a high sputtering rate, which results in active redeposition of the sputtered material onto the surface [12]. Obviously, over a fixed time, the higher sputtering rate enables the larger volume of the sputtered material above the surface. This leads to the deposition of the larger amount of building blocks and the more active growth of nanostructures takes place on the surface. The threshold sputtering energy $E_{\mathrm{th}}$ for the Ar-PbS pair was estimated to be approximately $10 \mathrm{eV}$ on the basis of known equations reported in literature [32] for sputtering of whole $\mathrm{PbS}$ molecules. Therefore, the energy range of argon ions of $25-200 \mathrm{eV}$ used in this work, resulting in $E_{\mathrm{i}} / E_{\mathrm{th}} \approx 2.5-20$. Table 1 shows the experimental dependence of the sputtering rate $\mathrm{V}$ of (100) PbS single crystals on the argon ion energy $E_{i}$. The sputtering rate was determined as the ratio of the etching step height at the interface between the sputtered and non-sputtered regions, which was measured using SEM, to the time of plasma treatment. Notably, the sputtering rate of the studied (100) PbS crystals at the ion energy of $25 \mathrm{eV}\left(0.1 \mathrm{~nm} \mathrm{~s}^{-1}\right)$ was much lower than that of single-crystal (111) $\mathrm{PbX}$ films (0.5 $\mathrm{nm} \mathrm{s}^{-1}$ at $E_{\mathrm{i}}=25 \mathrm{eV}$ for PbSe [25]). The very low etching rate at an energy of $25 \mathrm{eV}$ in this case may be due to the difficult sputtering of the thin, partially oxidized near-surface layer formed during mechanical polishing and chemical cleaning. Thus, an important feature of the experiment performed with $E_{\mathrm{i}}=25 \mathrm{eV}$ (in contrast with previous experiments on (111)-oriented $\mathrm{PbX}$ films [22-24]) was the low sputtering rate of the (100) $\mathrm{PbS}$ surface, which led to a smaller amount of sputtered material above the treated surface.

Table 1. Experimental dependence of the (100) PbS single crystal sputtering rate $\mathrm{V}$ on the average $\mathrm{Ar}^{+}$ion energy $E_{\mathrm{i}}$.

\begin{tabular}{ccccc}
\hline$E_{\mathrm{i}}(\mathrm{eV})$ & 25 & 75 & 100 & 200 \\
\hline$V(\mathrm{~nm} / \mathrm{s})$ & 0.1 & 3.3 & 5.8 & 10.8 \\
\hline
\end{tabular}

It is noteworthy that the surface temperature also plays an important role in the processes of nanostructuring during plasma treatment, which determines the mechanism of nanostructure formation. Obviously, increasing the ion energy and plasma treatment time increases the surface temperature. The sample temperature during plasma treatment can be increased by $100{ }^{\circ} \mathrm{C}$ using conditions of $E_{\mathrm{i}}=20-25 \mathrm{eV}$ and a treatment duration of $60 \mathrm{~s}$ [20] or by $230{ }^{\circ} \mathrm{C}$ with $E_{\mathrm{i}}=200 \mathrm{eV}$ and a duration of $30 \mathrm{~s}$ [12]; the much longer durations used in this work can be expected to result in even larger temperature increments.

Remarkably, the ion-plasma sputtering of lead chalcogenides can be described by two approaches. The first approach used by Zayachuk et al. [33] is based on the classical consideration of the interactions between ions and multi-component materials, which suggests that the sputtering predominantly involves individual atoms of certain chemical elements. The second approach, which was used in our previous studies [12] and applied again in this work, considers that the dissociation energies of molecules in the crystalline and gaseous states for lead chalcogenides exceed the values of the sublimation energy [34]. Therefore, during the sputtering of lead chalcogenides, whole molecules and their complexes predominantly leave the surface rather than individual atoms. Subsequently, these 
molecules dissociate under the influence of plasma UV emission (glow), and certain groups of atoms are effectively redeposited on the surface.

\subsection{Formation of Nanotips via the Micromasking Mechanism}

The initial state of the surface of (100) PbS crystals is shown in Figure 1a,b. Scratches from mechanical polishing are visible on the surface; irregularities in the areas between the scratches appear in the form of hillocks with lateral dimensions of up to $250 \mathrm{~nm}$ and heights of up to $40 \mathrm{~nm}$.
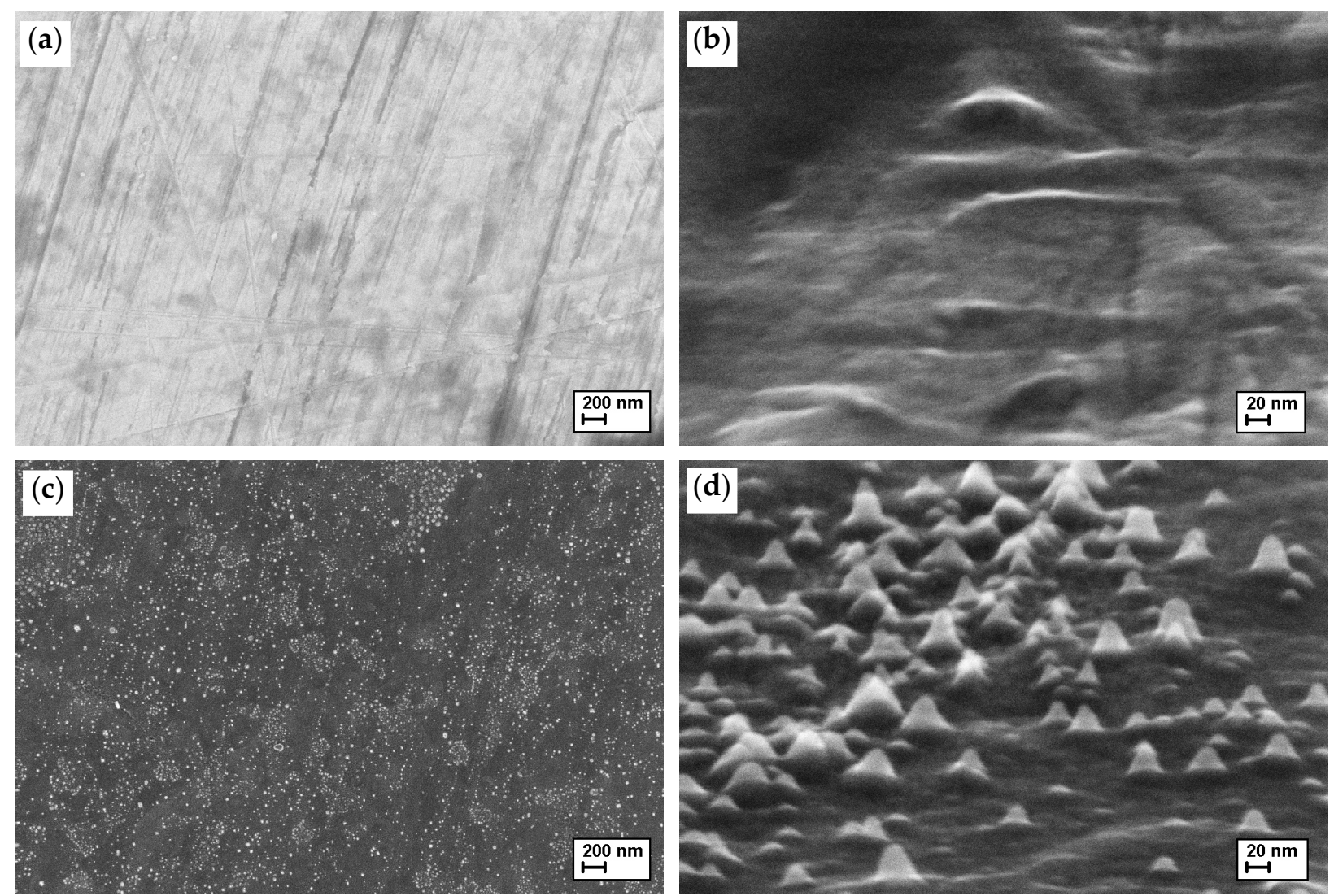

Figure 1. SEM images of the (a,b) initial and mechanically polished (100) PbS single crystal surface and $(\mathbf{c}, \mathbf{d})$ after plasma treatment with a minimal average ion energy $\mathrm{Ei}=25 \mathrm{eV}$ and a sputtering time of $360 \mathrm{~s}$. In (b,d), samples were tilted $70^{\circ}$ during SEM imaging.

The surface modification was then examined upon treatment at ions with a minimum energy of $25 \mathrm{eV}$ over a wide time range of 60-360 s. At the energy of bombarding ions $E_{\mathrm{i}}=25 \mathrm{eV}$, the PbS sputtering rate was minimal. Clusters of nanostructures on the surface emerged after treatments lasting $240 \mathrm{~s}$ and more. The surface morphology after the $360 \mathrm{~s}$ treatment is shown in Figure 1c,d, which shows nanostructures in the form of nanotips. These nanotips are up to 30 and $50 \mathrm{~nm}$ tall after 240 and $360 \mathrm{~s}$ plasma treatments, respectively, and their diameter at the base is roughly equal to their height. The dimensions of micro- and nanostructures formed under different conditions of plasma treatment are summarized in Table 2. The nanotips were not uniformly distributed over the surface (Figure 1c) but were preferentially localized along the lines of scratches. The number density of the nanostructures on the surface was measured from SEM data to be in the range of $(1-2) \times 10^{10} \mathrm{~cm}^{-2}$. 
Table 2. Dimensions of $\mathrm{PbS}$ and $\mathrm{Pb}$ micro- and nanostructures depending on the plasma treatment conditions.

\begin{tabular}{|c|c|c|c|}
\hline$E_{\mathrm{i}}(\mathrm{eV})$ & $\begin{array}{l}\text { Plasma Treatment } \\
\text { Duration (s) }\end{array}$ & $\begin{array}{l}\text { Surface Micro- and } \\
\text { Nanostructures }\end{array}$ & Formation Mechanism \\
\hline 25 & $240-360$ & $\begin{array}{l}\text { Nanocones with } 30-50 \mathrm{~nm} \\
\text { heights }\end{array}$ & $\begin{array}{l}\text { Micromasking with } \\
\mathrm{Pb} \text { particles }\end{array}$ \\
\hline \multirow{3}{*}{75} & 60 & $\begin{array}{c}200 \mathrm{~nm} \text { high submicron } \\
\text { cones; nanodroplets with } 50 \\
\text { nm diameters }\end{array}$ & $\begin{array}{l}\text { Micromasking of } \\
\text { dislocation exit sites; } \mathrm{Pb} \\
\text { droplet redeposition }\end{array}$ \\
\hline & 120 & $\begin{array}{l}400 \mathrm{~nm} \text { high submicron } \\
\text { cones; orthogonal } \\
\text { nanostructures with } 50 \mathrm{~nm} \\
\text { nanodroplets }\end{array}$ & $\begin{array}{l}\text { Micromasking of } \\
\text { dislocation exit sites; } \\
\text { VLS growth }\end{array}$ \\
\hline & 180 & $\begin{array}{c}\text { Arrays of larger } \\
\text { quasi-spherical metallic } \\
\text { structures; arrays of smaller } \\
\text { quasi-spherical particles }\end{array}$ & $\begin{array}{l}\text { Growth of hollow metallic } \\
\text { Pb structures [20] }\end{array}$ \\
\hline \multirow[b]{2}{*}{100,200} & 60 & $\begin{array}{l}350 \text { nm high submicron } \\
\text { cones; nanodroplets }\end{array}$ & $\begin{array}{c}\text { Micromasking of } \\
\text { dislocation exit sites; } \mathrm{Pb} \\
\text { droplet redeposition }\end{array}$ \\
\hline & 120 & $\begin{array}{l}700 \mathrm{~nm} \text { high submicron } \\
\text { cones; cruciform } \\
\text { nanostructures with } 35 \mathrm{~nm} \\
\text { nanodroplets }\end{array}$ & $\begin{array}{l}\text { Micromasking of } \\
\text { dislocation exit sites; } \\
\text { VLS growth }\end{array}$ \\
\hline 200 & $120+180$ & $\begin{array}{c}\text { Array of cruciform } \\
\text { nanostructures with heights } \\
\text { up to } 140 \mathrm{~nm} \text { with } 25-70 \mathrm{~nm} \\
\text { nanodroplets }\end{array}$ & VLS growth \\
\hline
\end{tabular}

The processes taking place under these plasma treatment conditions can be described physically as follows. During plasma sputtering, PbS molecules leave the surface and dissociate under the influence of plasma UV emission. As a result, lead atoms are deposited onto the surface, and owing to diffusion processes on the heated surface of the sample, they are collected in liquid-state nanodroplets. It is assumed that lead forms liquid droplets, because its melting point is low $\left(327^{\circ} \mathrm{C}\right)$ and nanosize particles have even lower melting point. Besides, a particle transits to a liquid state gradually, starting with a liquid outer layer, which can be formed at even lower temperatures. Such temperatures are achieved in the present plasma setup under long sputtering durations. The lead droplets are predominantly located on relief features and particularly on scratch lines. Such lead nanodroplets can act as nanomasks during the plasma etching process, leading to the formation of conical nanotips by the micromasking mechanism. This model is corroborated by the round shape of the tops of the nanotips (Figure 1d) and the fact that the height of the nanotips does not exceed the thickness of the sputtered layer. The possibility that the nanocones formed under these conditions are an initial stage of the VLS mechanism cannot be excluded.

\subsection{Submicron Cones and Arrays of Nanostructures}

With an increase in the ion energy to $75-200 \mathrm{eV}$, the modification behavior of the (100) PbS surface changed fundamentally with respect to the previous case. Figure 2 presents typical images of the surface morphology after surface treatment with $E_{\mathrm{i}}$ of 75, 100 and $200 \mathrm{eV}$ and treatment durations of 60-120 s. Notably, two new types of structures appear: high submicron cones (with submicron- and micron-scale heights) and arrays of nanostructures of various shapes. The number density of these submicron cones was $(0.8-1.2) \times 10^{8}, 2.5 \times 10^{7}$, and $(5-8) \times 10^{4} \mathrm{~cm}^{-2}$ for ion energies of 75, 100, and $200 \mathrm{eV}$, 
respectively, and they reached heights of 400, 700, and $1300 \mathrm{~nm}$, respectively, with base diameters of 140-900 nm.
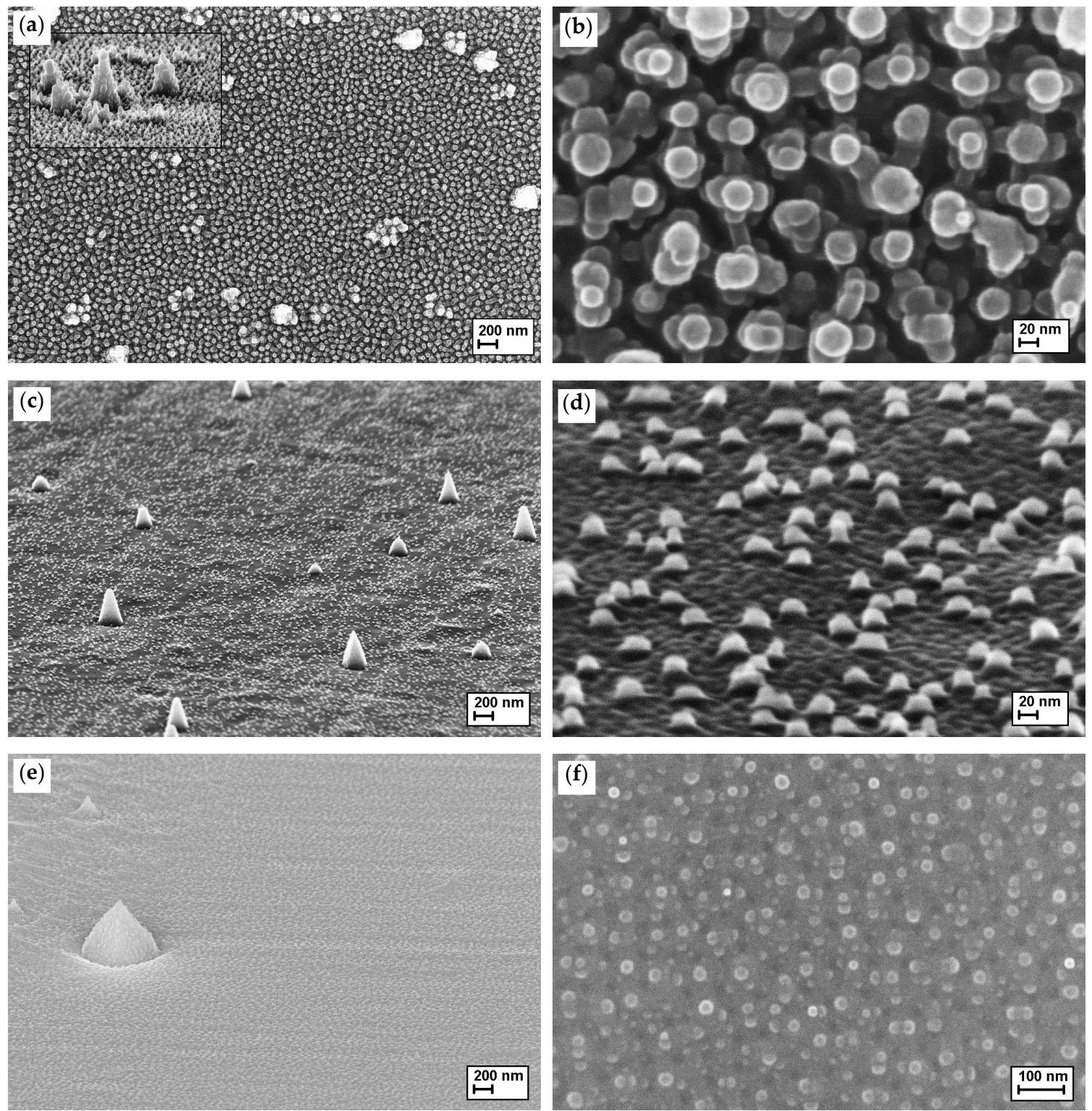

Figure 2. Low- (left) and high-magnification (right) SEM images of the (100) PbS single crystal surface after plasma treatment with ion energies and sputtering times of (a,b) $75 \mathrm{eV}$ for $120 \mathrm{~s},(\mathbf{c}, \mathbf{d}) 100 \mathrm{eV}$ for $60 \mathrm{~s}$, and (e,f) $200 \mathrm{eV}$ for $120 \mathrm{~s}$ respectively. The inset in (a) as well as (c-e) were obtained with a sample tilt of $70^{\circ}$.

The formation of submicron cones on single crystals and films of lead chalcogenides has been attributed to the micromasking of dislocation sites and discussed in detail in our previous works [22,35]. Notably, the maximum heights of these submicron cones strictly correspond to the thickness of the sputtered (removed) layer. This suggests that their formation begins in the initial stages of crystal surface sputtering in the areas where the sputtering rate was low, i.e., at the dislocations exit points, which thus serve as micromasks during the subsequent sputtering process. The number density of submicron cones at the ion energy of $75 \mathrm{eV}$ corresponds to the density of dislocations on the surface of the polished sample. However, at the ion energy of $200 \mathrm{eV}$, this density corresponds to the density of dislocations in the bulk of the crystal because of the removal of the mechanically 
damaged layer. Thus, the surface density of submicron cones is in good agreement with the dislocation density. When sputtering with ions of 75 and $100 \mathrm{eV}$, the thickness of the removed layer does not exceed the thickness of the mechanically damaged layer, which explains the high surface density of submicron cones. Local EDX analysis showed that the chemical compositions of the submicron cones and the initial crystal were identical, which validates the proposed mechanism of the formation of submicron cones owing to the effect of micromasking at the dislocation exit sites.

Figure $2 b, d$, f shows the shape of nanostructures formed on the surface areas between the submicron cones. The $60 \mathrm{~s}$ plasma treatment resulted in a homogeneous array of spherical lead nanodroplets on the surface. The sizes of these droplets did not exceed $\sim 50 \mathrm{~nm}$. Increasing the plasma treatment time to $120 \mathrm{~s}$ resulted in the formation of specific cruciform nanostructures with lateral orthogonal elements oriented in the four $<100>$ directions. At the top and in the center of an individual cruciform nanostructure, there was a lead drop of size up to $\sim 35 \mathrm{~nm}$, which catalyzed for the VLS mechanism during the vertical growth of the nanostructures, during which the redeposited PbS molecules formed an underlying solid crystal under the droplets. At the same time, the droplet catalyzed lateral branch growth in four orthogonal directions in the horizontal plane by the VLS mechanism. These directions correspond to the $<100>$ orientations, which have minimal growth energy. Another significant observation is that the VLS growth took place simultaneously with the ion bombardment, which limited the vertical growth. As a result, an array of unique, complex morphology nanostructures was formed with the nanobranches growing in the same directions. Surface chemistry studies using the EDX method while tilting the sample indicate that the surface was enriched with lead. For the sample grown with an ion energy and sputtering time of $75 \mathrm{eV}$ and $120 \mathrm{~s}$, respectively, as shown in Figure $2 \mathrm{a}, \mathrm{b}$, the $\mathrm{Pb} / \mathrm{S}$ ratio was 1.29 , while that of the initial surface was 1.04 . Thus, it can be concluded that the formation of arrays of cruciform nanostructures described here depends on the activation of the VLS mechanism. Thus, for plasma treatment times longer than $120 \mathrm{~s}$, the surface temperature and the volume of the sputtered material are sufficient for the VLS growth of nanostructures.

\subsection{Formation of Nanostructure Arrays without Submicron Cones}

The formation of micro- and nanostructure arrays described above has a practical disadvantage associated with the presence of submicron and microcones, as they would hinder the consecutive fabrication of multilayer systems. Therefore, plasma treatment conditions were selected in the present work to suppress the formation of microcones. This problem can be solved by an additional plasma treatment with a high ion energy for a longer time, during which the micromasking behavior of the dislocation exit sites is prevented owing to the high surface temperatures.

The present studies have shown that after two-step processing, submicron cones were completely absent on the treated surface, and the system of cruciform nanostructures with lateral orthogonal elements oriented in four $<100>$ directions was more pronounced than that after the one-step process (Figure 2). Figure 3 shows the surface morphology of a (100) $\mathrm{PbS}$ crystal treated with plasma at an ion energy $E_{\mathrm{i}}=200 \mathrm{eV}$ for $120 \mathrm{~s}$ as a first step and then for $180 \mathrm{~s}$ as a second step. The heights of the nanostructures reached $140 \mathrm{~nm}$, and the sizes of lead droplets at the top varied in the range of $25-70 \mathrm{~nm}$. The lateral branches in the $<100>$ directions were 20-60 $\mathrm{nm}$ long, and the surface density of the nanostructures was $5 \times 10^{9} \mathrm{~cm}^{-2}$. The possibilities of the formation of structures of this type through the VLS mechanism have been discussed in literature [36]. Branched individual nanostructures of $\mathrm{PbS}$ and $\mathrm{PbSe}$, similar in shape were previously obtained by chemical vapor deposition synthesis $[37,38]$. The technique used in the present work to form nanostructures imparts a vertical direction to the growth processes and then results in the formation of nanostructure elements in the same direction on the surface of the oriented (100) PbS substrate. 

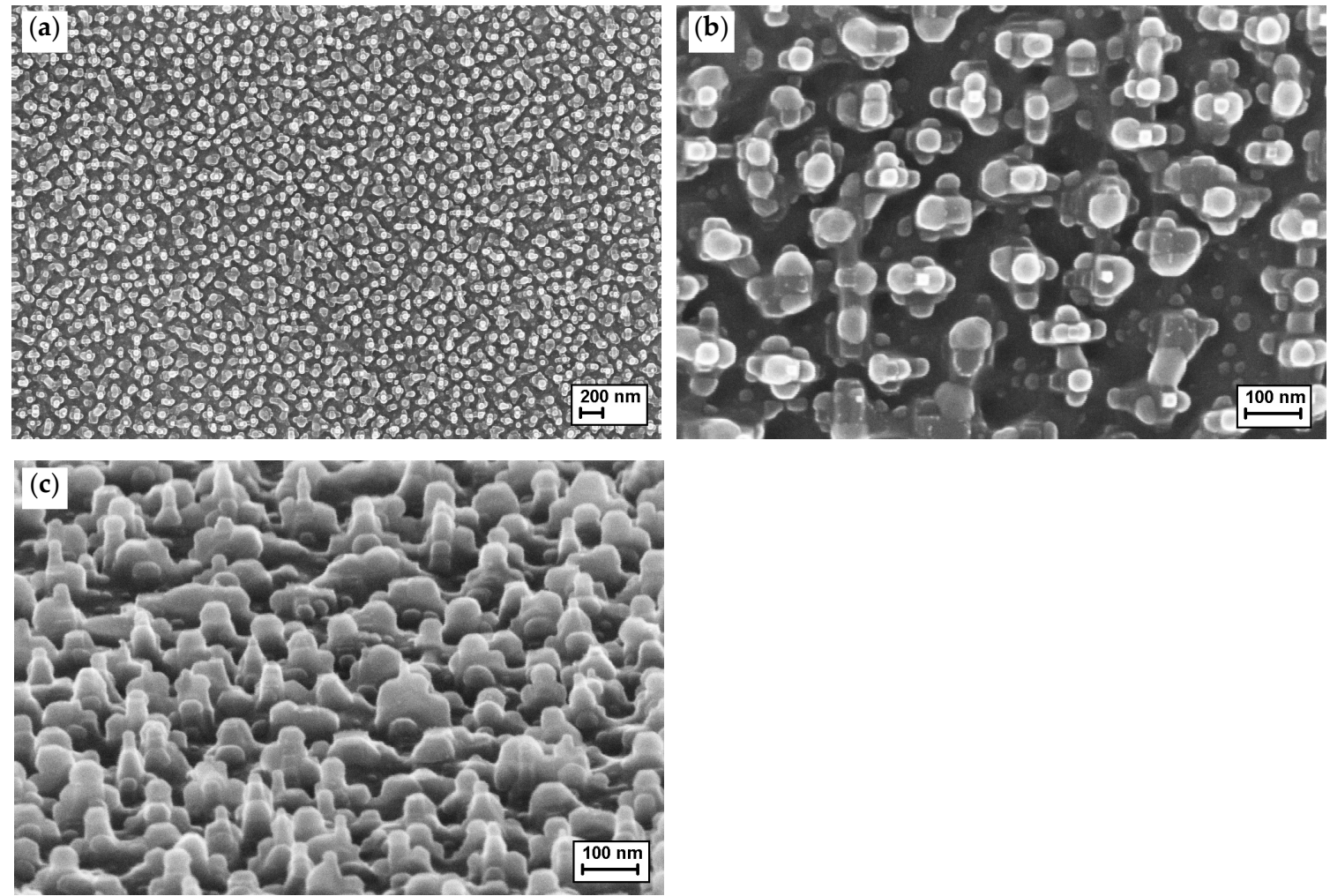

Figure 3. (a,b) Plane-view and (c) $70^{\circ}$-tilted SEM images of the (100) PbS single crystal surface after a two-step treatment with $E_{\mathrm{i}}=200 \mathrm{eV}$ for $120 \mathrm{~s}$ and $E_{\mathrm{i}}=200 \mathrm{eV}$ for $180 \mathrm{~s}$.

\subsection{Formation of Quasi-Spherical Lead Submicron Structures}

In our previous work, when studying the processes involved in the plasma sputtering of epitaxial (111) PbSe films near the sputtering threshold, an interesting phenomenon was discovered wherein arrays of hollow lead structures with a quasi-spherical shape and a submicron size were formed at an ion energy of $25 \mathrm{eV}$ during a long-time sputtering [20]. However, as described above for (100) PbS crystals, these plasma treatment conditions only led to the formation of ensembles of PbS nanotips under lead nanocaps (Figure 1). It can be concluded that the main reason for this is the extremely low surface sputtering rate, which results in a minimal amount of building blocks above the surface during processing. To increase the sputtering rate, an ion energy of $75 \mathrm{eV}$ has been used for the plasma treatment. Figure 4 shows an example of the surface morphology of (100) PbS crystals after treatment with argon plasma at an ion energy of $75 \mathrm{eV}$ for $180 \mathrm{~s}$.
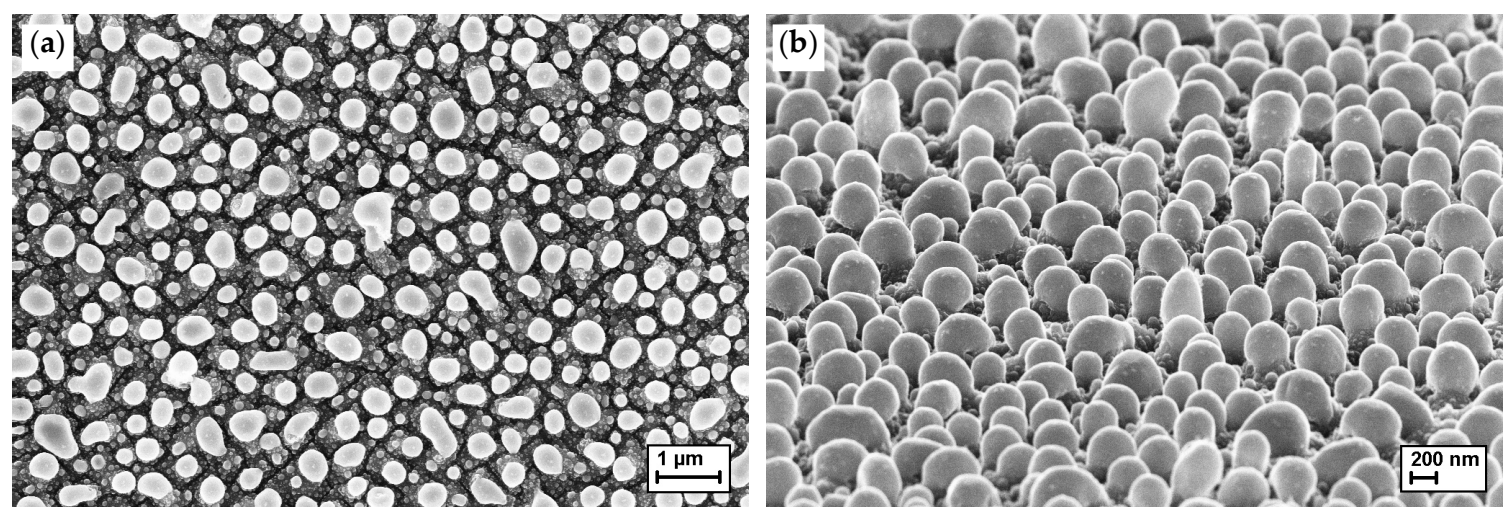

Figure 4. (a) Plane-view and (b) $70^{\circ}$-tilted SEM images of the (100) PbS single crystal surface after plasma treatment with $E_{\mathrm{i}}=75 \mathrm{eV}$ for $180 \mathrm{~s}$. 
The physical processes on the surface in this case were similar to those on the surface of lead selenide at $E_{\mathrm{i}}=25 \mathrm{eV}$ and a processing time of $180 \mathrm{~s}$ [20], specifically, arrays were formed by larger submicron quasi-spherical structures with diameters of 250-600 nm and number density of $2 \times 10^{8} \mathrm{~cm}^{-2}$ as well as smaller quasi-spherical structures with diameters of up to $75 \mathrm{~nm}$.

Local EDX studies (Figure 5) of the surface of PbS crystals after plasma treatment $\left(E_{\mathrm{i}}=75 \mathrm{eV}\right.$, time $\left.180 \mathrm{~s}\right)$ revealed that for the submicron quasi-spherical structures the $\mathrm{Pb} / \mathrm{S}$ ratio was at least 5.3. In the areas between these large particles, this ratio was less than 1.2, indicating more lead was found on the surface than that in the initial state (1.04). Therefore, as previously reported in our work [20], submicron quasi-spherical lead structures were formed on the surface of $\mathrm{PbS}$ crystals.
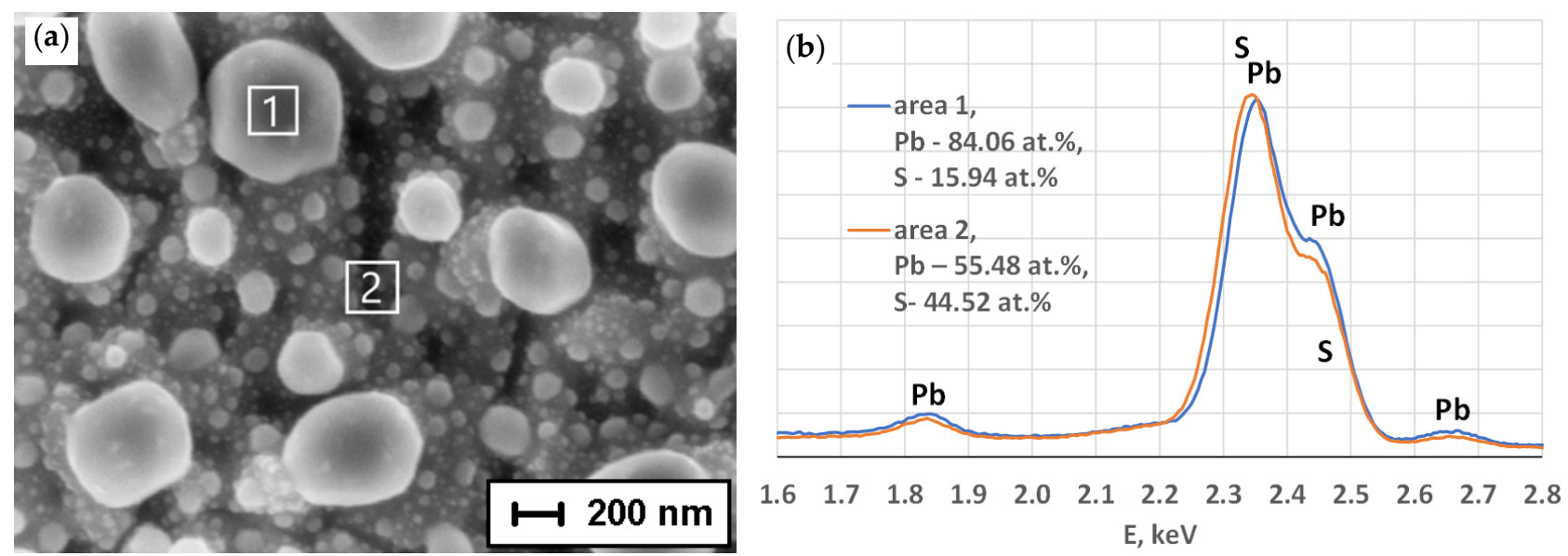

Figure 5. (a) Areas and (b) the corresponding results of EDX analysis of the (100) PbS single crystal surface after plasma treatment with $E_{\mathrm{i}}=75 \mathrm{eV}$ for $180 \mathrm{~s}$.

\section{Conclusions}

This study showed that a slight variation in the conditions of the argon plasma treatment method, enables reproducibly obtaining various nano- and microstructures on the surface of (100) PbS crystals. Remarkably, the plasma treatment resulted in fundamentally new structures on the surface, such as cruciform structures with a droplet center, which have not yet been obtained by other known methods. These structures were attributed to specific conditions during plasma treatment that initiated a surface micromasking mechanism during lead formation and/or activated the VLS mechanism, wherein liquid lead droplets also acted as self-forming growth catalysts. Changes in the sputtering rate (via the ion energy) and surface temperature (through the sputtering time) contributed to instigating certain physical mechanisms of nano- and microrelief formation. As a result of plasma treatment, the removal processes of material in the form of molecules and clusters, dissociation of these molecules, redeposition of building blocks on a surface heated to various temperatures, and crystalline growth all occur simultaneously. These findings, thus demonstrate that the VLS mechanism can be realized during plasma treatment without the use of special catalysts. In the plasma-assisted process, the lead contained in the sputtered material works well as a self-forming catalyst. The resulting micro- and nanostructures are essentially nanocomposites of $\mathrm{PbS}$ structures and $\mathrm{Pb}$-enriched catalytic particles. The nanostructures obtained from a solution require an additional step for depositing them on a substrate, whereas in the plasma treatment method, ensembles of nanostructures form automatically on the surface of the functional layer with good adhesion, which is a primary advantage of the proposed technique. Notably, other conditions can be applied to plasma treatment to enable further micro- and nanostructuring, such as multi-step processes and substrate cooling. Considering that plasma modification processes have their own specific features for various lead chalcogenides and solid solutions based on them, the field of 
ion-plasma treatment for $\mathrm{PbX}$ materials should be further studied in order to expand the possibilities of forming nanostructured surfaces with desired properties.

Author Contributions: Conceptualization, S.P.Z. and N.-H.K.; methodology, S.P.Z. and N.-H.K.; investigation, N.N.K., I.I.A., V.V.N., E.S.G. and S.K.; data curation, I.I.A. and S.P.Z.; writing-original draft preparation, S.P.Z.; writing - review and editing, S.K. and N.-H.K.; supervision, S.P.Z. and N.-H.K.; project administration, S.P.Z.; funding acquisition, I.I.A., N.N.K. and N.-H.K. All authors have read and agreed to the published version of the manuscript.

Funding: The investigation was supported by the Program no. FFNN-2022-0017 of the Ministry of Science and Higher Education of Russia for Valiev Institute of Physics and Technology of RAS. This research was partially funded by the RF State task of ISSP RAS. This work including the APC was funded by the Gwangju·Jeonnam Local Energy Cluster Manpower Training of the Korea Institute of Energy Technology Evaluation and Planning (KETEP) grant funded by the Korea government Ministry of Trade, Industry and Energy (No. 20214000000560).

Data Availability Statement: Data are contained within the article.

Acknowledgments: SEM investigations were carried out at the Facilities Sharing Centre "Diagnostics of Micro- and Nanostructures" with the support of the Ministry of Science and Higher Education of Russian Federation.

Conflicts of Interest: The authors declare no conflict of interest. The founding sponsors had no role in the design of the study; in the collection, analyses, or interpretation of data; in the writing of the manuscript, and in the decision to publish the results.

\section{References}

1. Xiao, G.; Wang, Y.; Ning, J.; Wei, Y.; Liu, B.; William, W.Y.; Zou, G.; Zou, B. Recent advances in IV-VI semiconductor nanocrystals: Synthesis, mechanism, and applications. RSC Adv. 2013, 3, 8104-8130. [CrossRef]

2. Litvin, A.P.; Martynenko, I.V.; Purcell-Milton, F.; Baranov, A.V.; Fedorov, A.V.; Gun'Ko, Y.K. Colloidal quantum dots for optoelectronics. J. Mater. Chem. A 2017, 5, 13252-13275. [CrossRef]

3. Wang, L.; Wang, Y.; Jia, Y.; Liu, X.; Liu, T.; Fu, T.; Li, J.; Weng, B.; Zhang, X.; Liu, Y. Manipulation of Phase-Transfer LigandExchange Dynamics of PbS Quantum Dots for Efficient Infrared Photovoltaics. J. Phys. Chem. C 2019, 123, 30137-30144. [CrossRef]

4. Zhang, X.; Zhang, J.; Phuyal, D.; Du, J.; Tian, L.; Öberg, V.A.; Johansson, M.B.; Cappel, U.B.; Karis, O.; Liu, J.; et al. Inorganic $\mathrm{CsPbI}_{3}$ perovskite coating on $\mathrm{PbS}$ quantum dot for highly efficient and stable infrared light converting solar cells. Adv. Energy Mater. 2018, 8, 1702049. [CrossRef]

5. Sukharevska, N.; Bederak, D.; Goossens, V.M.; Momand, J.; Duim, H.; Dirin, D.N.; Kovalenko, M.V.; Kooi, B.J.; Loi, M.A. Scalable PbS Quantum Dot Solar Cell Production by Blade Coating from Stable Inks. ACS Appl. Mater. Interfaces 2021, 13, 5195-5207. [CrossRef]

6. Jana, S.; Goswami, S.; Nandy, S.; Chattopadhyay, K.K. Synthesis of tetrapod like PbS microcrystals by hydrothermal route and its optical characterization. J. Alloy. Compd. 2009, 481, 806-810. [CrossRef]

7. Murray, C.B.; Sun, S.; Gaschler, W.; Doyle, H.; Betley, T.A.; Kagan, C.R. Colloidal synthesis of nanocrystals and nanocrystal superlattices. IBM J. Res. Dev. 2001, 45, 47-56. [CrossRef]

8. Bakueva, L.; Gorelikov, I.; Musikhin, S.; Zhao, X.S.; Sargent, E.H.; Kumacheva, E. PbS quantum dots with stable efficient luminescence in the near-IR spectral range. Adv. Mater. 2004, 16, 926-929. [CrossRef]

9. Alchalabi, K.; Zimin, D.; Kostorz, G.; Zogg, H. Self-assembled semiconductor quantum dots with nearly uniform sizes. Phys. Rev. Lett. 2003, 90, 026104. [CrossRef]

10. Anthony, S.P.; Cho, W.J.; Lee, J.I.; Kim, J.K. Synthesis of lead chalcogenide nanoparticles in block copolymer micelles: Investigation of optical properties and fabrication of 2-D arrays of nanoparticles. J. Mater. Chem. 2009, 19, 280-285. [CrossRef]

11. Dong, G.; Wu, B.; Zhang, F.; Zhang, L.; Peng, M.; Chen, D.; Wu, E.; Qiu, J. Broadband near-infrared luminescence and tunable optical amplification around $1.55 \mu \mathrm{m}$ and $1.33 \mu \mathrm{m}$ of PbS quantum dots in glasses. J. Alloy. Compd. 2011, 509, 9335-9339. [CrossRef]

12. Zimin, S.; Gorlachev, E.; Amirov, I. Inductively Coupled Plasma Sputtering: Structure of IV-VI Semiconductors. In Encyclopedia of Plasma Technology, 1st ed.; Shohet, J.L., Ed.; CRC Press: New York, NY, USA, 2017; pp. 679-691. Available online: https: //www.routledgehandbooks.com/doi/10.1081/E-EPLT-120053966 (accessed on 1 November 2020).

13. Gago, R.; Vázquez, L.; Cuerno, R.; Varela, M.; Ballesteros, C.; Albella, J.M. Production of ordered silicon nanocrystals by low-energy ion sputtering. Appl. Phys. Lett. 2001, 78, 3316-3318. [CrossRef]

14. Levchenko, I.; Ostrikov, K. Nanostructures of various dimensionalities from plasma and neutral fluxes. J. Phys. D: Appl. Phys. 2007, 40, 2308-2319. [CrossRef] 
15. Bradley, R.M.; Shipman, P.D. Spontaneous pattern formation induced by ion bombardment of binary compounds. Phys. Rev. Lett. 2010, 105, 145501. [CrossRef] [PubMed]

16. Singh, U.B.; Agarwal, D.C.; Khan, S.A.; Kumar, M.; Tripathi, A.; Singhal, R.; Panigrahi, B.K.; Avasthi, D.K. Engineering of hydrophilic and plasmonic properties of Ag thin film by atom beam irradiation. Appl. Surf. Sci. 2011, 258, 1464-1469. [CrossRef]

17. Tanyeli, I.; Marot, L.; Mathys, D.; van de Sanden, M.C.M.; De Temmerman, G. Surface modifications induced by high fluxes of low energy Helium ions. Sci. Rep. 2015, 5, 9779. [CrossRef] [PubMed]

18. Sulania, I.; Agarwal, D.; Husain, M.; Avasthi, D.K. Investigations of ripple pattern formation on Germanium surfaces using 100-keV Ar ${ }^{+}$ions. Nanoscale Res. Lett. 2015, 10, 88. [CrossRef]

19. El-Said, A.S.; Wilhelm, R.A.; Heller, R.; Sorokin, M.; Facsko, S.; Aumayr, F. Tuning the fabrication of nanostructures by low-energy highly charged ions. Phys. Rev. Lett. 2016, 117, 126101. [CrossRef]

20. Zimin, S.P.; Amirov, I.I.; Naumov, V.V.; Guseva, K.E. The Formation of Hollow Lead Structures on the Surface of PbSe Films Treated in Argon Plasma. Tech. Phys. Lett. 2018, 44, 518-521. [CrossRef]

21. Zimin, S.P.; Amirov, I.I.; Naumov, V.V. Changes in the conductivity of lead-selenide thin films after plasma etching. Semiconductors 2016, 50, 1125-1129. [CrossRef]

22. Zimin, S.P.; Gorlachev, E.S.; Amirov, I.I.; Zogg, H. Micromasking effect and nanostructure self-formation on the surface of lead chalcogenide epitaxial films on Si substrates during argon plasma treatment. J. Phys. D-Appl. Phys. 2009, 42, 165205. [CrossRef]

23. Zimin, S.P.; Gorlachev, E.S.; Amirov, I.I.; Naumov, V.V.; Bagiyeva, G.Z. Application of abnormally high sputtering rate of PbTe (Te) single crystals during inductively coupled argon plasma treatment for fabrication of nanostructures. Semicond. Sci. Technol. 2015, 30, 035017. [CrossRef]

24. Zimin, S.P.; Gorlachev, E.S.; Amirov, I.I.; Naumov, V.V.; Juskenas, R.; Skapas, M.; Abramof, E.; Rappl, P.H.O. Plasma-assisted surface nanostructuring of epitaxial $\mathrm{Pb}_{1-\mathrm{x}} \mathrm{Sn}_{\mathrm{x}} \mathrm{Te}(0 \leq \mathrm{x} \leq 1)$ films. Semicond. Sci. Technol. 2019, 34, 095001. [CrossRef]

25. Zimin, S.P.; Amirov, I.I.; Naumov, V.V.; Guseva, K.E. Surface Modification of $\mathrm{Pb}_{1-\mathrm{x}} \mathrm{Sn}_{\mathrm{x}}$ Se Films during Plasma Treatment Near the Sputtering Threshold. J. Surf. Ingestig.-X-Ray Synchro. 2020, 14, 1174-1178. [CrossRef]

26. Zimin, S.P.; Gorlachev, E.S.; Gremenok, V.F.; Tsyrelchuk, I.N.; Naumov, V.V.; Amirov, I.I.; Dubov, G.A. Plasma sputtering of polycrystalline $\mathrm{Pb}_{1-} \mathrm{Sn}_{\mathrm{x}} \mathrm{Te}$ thin films grown on glass substrates using hot wall deposition. Semicond. Sci. Technol. 2014, 29, 075020. [CrossRef]

27. Zimin, S.P.; Gorlachev, E.S.; Amirov, I.I.; Naumov, V.V. Lead selenide nanowire growth by vapor-liquid-solid mechanism under mask during plasma processing. Tech. Phys. Lett. 2011, 37, 929-931. [CrossRef]

28. Wang, Y.; Yang, X.; Xiao, G.; Zhou, B.; Liu, B.; Zou, G.; Zou, B. Shape-controlled synthesis of PbS nanostructures from- 20 to 240 ${ }^{\circ} \mathrm{C}$ : The competitive process between growth kinetics and thermodynamics. Crystengcomm 2013, 15, 5496-5505. [CrossRef]

29. Lee, S.M.; Jun, Y.W.; Cho, S.N.; Cheon, J. Single-crystalline star-shaped nanocrystals and their evolution: Programming the geometry of nano-building blocks. J. Am. Chem. Soc. 2002, 124, 11244-11245. [CrossRef]

30. Gerdes, F.; Volkmann, M.; Schliehe, C.; Bielewicz, T.; Klinke, C. Sculpting of lead sulfide nanoparticles by means of acetic acid and dichloroethane. Z. Phys. Chem. 2015, 229, 139-151. [CrossRef]

31. Kolesnikov, N.N.; James, R.B.; Berzigiarova, N.S.; Kulakov, M.P. HPVB-and HPVZM-shaped growth of CdZnTe, CdSe, and ZnSe crystals. In X-Ray and Gamma-Ray Detectors and Applications IV, Proceedings of International Symposium on Optical Science and Technology, Seattle, WA, United States, 7-11 July 2002; James, R.B., Franks, L.A., Burger, A., Westbrook, E.M., Durst, R.D., Eds.; SPIE: Bellingham, WA, USA, 2003; Volume 4784, pp. 93-104. [CrossRef]

32. Bohdansky, J.; Roth, J.; Bay, H.L. An analytical formula and important parameters for low-energy ion sputtering. J. Appl. Phys. 1980, 51, 2861-2865. [CrossRef]

33. Zayachuk, D.M.; Slynko, V.E.; Csik, A. Peculiar properties of preferential sputtering of PbTe, SnTe, and GeTe by Ar+ ion plasma. Mater. Sci. Semicond. Process 2018, 88, 103-108. [CrossRef]

34. Zimin, S.P.; Amirov, I.I.; Gorlachev, E.S. RF sputtering of epitaxial lead chalcogenide films in argon and krypton plasma. Semicond. Sci. Technol. 2011, 26, 055018. [CrossRef]

35. Zimin, S.P.; Gorlachev, E.S.; Amirov, I.I.; Gerke, M.N.; Zogg, H.; Zimin, D. Role of threading dislocations during treatment of PbTe films in argon plasma. Semicond. Sci. Technol. 2007, 22, 929. [CrossRef]

36. Cheng, C.; Fan, H.J. Branched nanowires: Synthesis and energy applications. Nano Today 2012, 7, 327-343. [CrossRef]

37. Bierman, M.J.; Lau, Y.A.; Jin, S. Hyperbranched PbS and PbSe nanowires and the effect of hydrogen gas on their synthesis. Nano lett. 2007, 7, 2907-2912. [CrossRef] [PubMed]

38. Bierman, M.J.; Jin, S. Potential applications of hierarchical branching nanowires in solar energy conversion. Energy Environ. Sci. 2009, 2, 1050-1059. [CrossRef] 